\title{
Copyright
}

by

Xiaoran Liu

2018 
The Thesis Committee for Xiaoran Liu

Certifies that this is the approved version of the following thesis:

\section{Using the Binomial Model for the Valuation of Real Options in Computing Optimal Subsidies for Chinese Renewable Energy Investments}

\section{APPROVED BY}

SUPERVISING COMMITTEE:

John C. Butler, Supervisor

Ehud I. Ronn, Co-Supervisor

Carey W. King 


\title{
Using the Binomial Model for the Valuation of Real Options in Computing Optimal Subsidies for Chinese Renewable Energy Investments
}

\author{
by
}

\section{Xiaoran Liu}

\section{THESIS}

Presented to the Faculty of the Graduate School of

The University of Texas at Austin

in Partial Fulfillment

of the Requirements

for the Degree of

MASTER OF SCIENCE IN ENERGY AND EARTH RESOURCES

THE UNIVERSITY OF TEXAS AT AUSTIN

May 2018 


\section{Acknowledgments}

I would like to thank Dr. Ehud Ronn for his guidance and support, and Dr. John Butler and Dr. Carey King for their insights and advice. I would also like to thank my parents and friends for their unfailing support and continuous encouragement. 


\title{
Using the Binomial Model for the Valuation of Real Options in Computing Optimal Subsidies for Chinese Renewable Energy Investments
}

\author{
Xiaoran Liu, M.S.E.E.R \\ The University of Texas at Austin, 2018 \\ Supervisors: John C. Butler \\ Ehud I. Ronn
}

\begin{abstract}
For the valuation and implementation of renewable energy investments, the issue of providing private investors with a financial incentive to accelerate their investment is frequently a critical component. We apply this principle to the Chinese context. This paper focuses on using the binomial model to compute the required subsidy that would incentivize investors to optimal immediate exercise of the American-style option embedded in the operation of the projects for Chinese renewable energy investments. In addition, this paper also aims at contrasting the binomial model with the more-laborious Monte-Carlo simulation previously used to evaluate the proper subsidy. By using the same data but a different method, and reducing the number of uncertain factors to one, it is suggested these two methods have similar outcomes but the binomial method requires substantially less computation and is more self-explanatory. This paper thus provides government with an easy-to-implement alternative way to compute the required subsidy.
\end{abstract}




\section{Table of Contents}

Acknowledgments $\quad$ iv

Abstract $\quad$ v

List of Tables $\quad$ vii

List of Figures viii

$\begin{array}{lll}\text { Chapter 1. Introduction } & 1\end{array}$

Chapter 2. Research Method and Literature Review 4

2.1 Real Options Method . . . . . . . . . . . . . . . . . . 4

2.2 Different Option Pricing Method . . . . . . . . . . . . . 6

$\begin{array}{llr}\text { Chapter 3. Data Source } & 8\end{array}$

$\begin{array}{ll}\text { Chapter 4. Valuation Model } & 10\end{array}$

4.1 Model Description . . . . . . . . . . . . . . . . . . . . . . . . . 10

4.2 Electricity Production Value $P_{0} \ldots \ldots \ldots \ldots \ldots \ldots$

4.3 Project Value $V$ and Volatility $\sigma \ldots \ldots \ldots \ldots$

$\begin{array}{lll}\text { Chapter 5. } & \text { Result Analysis } & 17\end{array}$

$\begin{array}{lll}\text { Chapter 6. Conclusion } & 22\end{array}$

$\begin{array}{ll}\text { Appendix } & 23\end{array}$

$\begin{array}{ll}\text { References } & 25\end{array}$ 


\section{List of Tables}

3.1 Main Uncertain Factors . . . . . . . . . . . . . . . . . . . . . . . . . 9

3.2 Other Parameters Used In the Model . . . . . . . . . . . . . . . . . . . 9

5.1 DerivaGem Results of Subsidy . . . . . . . . . . . . . . . . 20

5.2 Results Comparison . . . . . . . . . . . . . . . . . . . . 21 


\section{List of Figures}

4.1 Early Exercise Condition . . . . . . . . . . . . . . . . 16

A.1 DerivaGem Display . . . . . . . . . . . . . . . 24 


\section{Chapter 1}

\section{Introduction}

Due to rapid economic growth, energy issues, such as air pollution, which are caused by increasing energy demands, have become a priority in China's agenda. China has become the world's largest energy consumer and greenhouse gas emitter, and IEA (International Energy Agency) predicts that the primary energy demands will double from 2005 to 2030. However, China's energy structure for the supply sector has relied heavily on fossil fuels, especially coal, which may result in issues of pollution, unsustainability, climate change, and declining energy security. China is trying to diversify its energy supply from traditional energy resources, such as fossil fuels, to new energy resources, including nuclear power and renewable energy, such as hydro, wind and solar power. China also promised in the Paris Agreement that it will peak its carbon emissions and reduce its carbon intensity by $60-65 \%$ of the 2005 level by 2030. There is an aggressive forecast that says China could achieve a renewable energy share of $60 \%$ and $86 \%$ renewable electricity by 2050 (Yang et al., 2016). China has implemented several measures to reach its goals, including a national carbon cap-and-trade program, a green dispatch policy, and a cap on coal consumption as part of its 13th Five-Year Plan for 2016 to 2020 (NRDC, 2017). Besides, China has made efforts for electricity market reform, including launching carbon market, issuing green certificates and setting provincial renewable energy quotas. As the world's largest clean energy investor, China has reach to 132.6 billion dollars in clean energy in- 
vestment (BNEF, 2018) and also plans to increase the installed capacity of wind and solar power to around $200 \mathrm{GW}$ and $150 \mathrm{GW}$ respectively by 2020 . These ambitious targets bring huge business opportunities to renewable energy investors, manufacturers and developers (Mariyana, 2015).

The subsidy is believed by public to be one of the main drivers in renewable energy development. External incentives are needed for compensating the high pay back period and different kinds of risks - technical, business, legal and policy - for renewable energy projects (Gatzert and Kosub, 2016), thus driving the renewable energy investment. There are different types of renewable energy subsidies around the world, such as feed-in tariff (FIT), rebate, renewable energy credit (REC) and premiums. In China, the FIT is mainly used. There are several previous studies about valuing subsidies policies, and most of them mainly used the quantitive analysis method, cost-benefit analysis method and net present value (NPV)(Zhang, 2017). M.M. Zhang, D.Q. Zhou, P. Zhou, H.T. Chen (2017) used the financial instrument- real options method to figure out what is the optimal level of subsidy for renewable energy investors in China, what are the effects of relevant factors on subsidy, and how should the government adjust policies to attract more renewable energy investments by paying less subsidy.

There are several ways to solve the real options. Zhang et al. used the least squared Monte Carlo (LSM) method to value embedded real options and solve the model. Instead, we used the binomial model which requires less computation and is easier to implement. Besides, we also focus on methods and results comparison. This paper is now organized as follows. Section 2 introduces the real options method and summarizes past research regarding the application of it in energy sections. Section 3 presents the data source. Section 
4 presents the details of valuation model and the derivation of the parameters. Section 5 presents the calculation and analysis of results. Section 6 summarizes the outcomes of this research. 


\section{Chapter 2}

\section{Research Method and Literature Review}

\subsection{Real Options Method}

Real options method accounts for both pure cost and opportunity cost, which are caused by future uncertainties (Zhang, 2017). Compared to the NPV method which only captures the value of a project at a specific time and within a specific period, the real options method incorporates the value of flexibility to respond to the changes in the market environment. This method is an advanced valuation technique that enables investors to take advantage of market opportunities, and at the same time avoiding or reducing losses if future conditions evolve adversely (Pringles et al., 2015). Here is a simple example, assume the NPV of a solar project is $\$ 1000$, which only accounts for the value of the project today. Due to electricity price fluctuations, the investor can choose to start the project when the electricity price is higher, thus bringing in more revenue. This flexibility brings extra value to the project, so that might end up higher than $\$ 1000$ using the real options method. The valuation approach of real options has become important in modern financial theory, combining as it does the powerful tools of option-valuation with the critically important issues of valuation and hedging of real assets (Ronn, 2004). In an efficient market, spot and forward energy prices are set by agents acting legally in a competitive marketplace. The power of option theory applied to this arena permits the optimization and valuation of the flexibilities embedded in the operation of energy projects owners (Ronn, 2004). In this 
way, competitive markets deliver the desirable triad of optimal resource allocation due to efficient price-signaling, proper assessment and mitigation of risk and the informativeness of competitive price-discovery (Ronn, 2004).

There have been several important papers that applied real options method to the oil field. McDonald and Siegel (1986) and Paddock et al. (1988) studied the optimal timing of investment where the benefits from the project and the investment cost follow continuous-time stochastic processes, and extended the financial theory to a real asset offshore petroleum. Schwartz (1997) and Schwartz and Smith (2000) addressed the imperative issue of sources of uncertainty in the oil futures markets, and applied the model to some hypothetical oil-related assets. Litzenberger and Rabinowitz (1995) emphasized the normal backwardation in oil futures contracts as an incentive for oil producers to extract oil. ${ }^{1}$ Besides, there are several studies using the real options method in the renewable energy investment area. Fleten et al. (2016) compared real options and net present value methods in green electricity investments. Boomsma et al. (2012) adopted a real options approach to analyze investment timing and capacity choice for renewable energy projects under FIT and renewable certificate trading support schemes. Pringles et al. (2014) valued power transmission investments by stochastic simulation using the real options method. Yang et al. (2007) evaluated the power investment options with uncertainty in climate policy. Fernandes et al. (2011) reviewed current state of the application of the real options approach in renewables and non-renewables.

\footnotetext{
${ }^{1}$ When the cross-sectional forward curve is downward-sloping — i.e., distant futures prices are lower than those of futures contracts closer to maturity - then the forward curve is said to be in backwardation.
} 


\subsection{Different Option Pricing Method}

After identifying real options embedded in the projects, we need to know the option types and value it using the proper method. There are two types of options, American style and European style. The difference is that the American style option can be exercised at any time prior to and including its maturity but the European style option can only be exercised at its maturity. Since investors can operate the project anytime before the maturity, the option we talk about is identified as the American style option. There are many different methods to come up with the estimate of European option values using the same underlying stochastic method - Geometric Brownian Motion (GBM). The most popular methods includes Black-Scholes, binomial model, Monte Carlo simulation. There have been studies that prove Monte Carlo results converge to Blacks-Scholes and binomial model results also converge to Black Scholes for European style option (Hon, 2012). We can conclude that these methods should produce the exact same values ignoring numerical issues. Although Monte Carlo and binomial values should be the same, binomial value converges more quickly.

For pricing American style option, a number of Monte Carlo simulation-based approaches have been proposed in the past decades (Jia, 2009). However, there are several deficiencies when applying the Ordinary Least Squares (OLS) regression method in Monte Carlo simulation for the American style option. When the number of simulation paths is small, when the number of functions in the approximation scheme is large, when European option prices are included in the approximation scheme, and when the number of exercise opportunities is large, the OLS in Monte Carlo simulation will have poor performance (Tompaidis and Yang, 2005). Based on these research, an alternative way - the binomial 
method is introduced in our article to eliminate the weakness of the Monte Carlo method. Since computational time will increase exponentially if we have many stochastic factors when using the binomial model, we reduce uncertainties into a one-factor model. 


\section{Chapter 3}

\section{Data Source}

The data we used (Table 3.1 and Table 3.2) was replicated from Zhang et al. (2017) for the ability to compare results for different methods. With the same inputs, we compare different methods. They used three uncertainty factors and the Monte Carlo method, and we reduce uncertainties into a one-factor model and use the binomial model. In this case, we need to closely adhere to their data in order to make the results comparable. The parameters and data are for the solar power plant in China. 
Table 3.1: Main Uncertain Factors

\begin{tabular}{|c|c|c|c|c|c|}
\hline Parameters & Variables & Initial Value & Drift Rate & Volatility & Source \\
\hline Market Price of Electricity & $S_{0}$ & $0.43 \mathrm{RMB} / \mathrm{kWh}$ & 0.02 & 0.02 & $\begin{array}{l}\text { NDRC; Zhou et al., } \\
\text { 2014; Zhang et al, } \\
2016\end{array}$ \\
\hline $\mathrm{CO}_{2}$ Price & $p_{0}$ & $0.12 \mathrm{RMB} / \mathrm{kWh}$ & 0.02 & 0.03 & $\begin{array}{l}\text { Zhu and Fan, 2011; } \\
\text { Zhang et al., 2016; In- } \\
\text { sley, } 2002\end{array}$ \\
\hline Unit Investment Cost & $k_{0}$ & $12000 \mathrm{RMB} / \mathrm{kW}$ & -0.06 & 0.04 & $\begin{array}{l}\text { Zhang et al., 2016; } \\
\text { Zhang et al., 2013; } \\
\text { Insley, 2002; CPIA, } \\
2013\end{array}$ \\
\hline
\end{tabular}

Table 3.2: Other Parameters Used In the Model

Variables

Unit Operation and Maintenance Cost Unit Generating Capacity

The Rate of Corporate Income Tax

The Rate of Value-added Tax

Magnitude of Installed Capacity

Discount Rate

Annual Decline Rate of the Unit Generating Capacity

Lifetime of Power Generation Project

$\begin{array}{cc}\text { uomc } & 0.2 \mathrm{RMB} / \mathrm{kWh} \\ \text { ugc } & 1500 \mathrm{kWh} \\ \tau & 25 \% \\ \pi & 8.25 \% \\ \mathrm{IC} & 1 \mathrm{~kW} \\ \mathrm{r} & 8 \% \\ \text { N/A } & 2 \% \\ \text { N/A } & 25 \text { years }\end{array}$

Zhang et al., 2017

Zhang et al., 2016

Government Law, 2013

Government Law, 2007

Zhang et al., 2017

Zhang et al., 2016

Zhang et al., 2016

Zhang et al., 2017 


\section{Chapter 4}

\section{Valuation Model}

\subsection{Model Description}

We use DerivaGem software and Excel to build our model.

Consider the application of real options methodology,

$$
C=C(V, K, r, \sigma, T, N)
$$

In eq. (4.1),

$C=$ Value of American-style call option on a futures contract

$V=$ After-tax value of the project, including electricity generation, subsidy and carbon credits

$K=$ Investment Cost of the project

$r=$ Riskfree rate, $r=8 \%$

$\sigma=$ Embedded volatility of project value

$T=$ Time to maturity (length of option, 16 years)

$N=$ No. of Time Steps in valuation $(N \leq 500$ in DerivaGem software; if you'd like to see the binomial model itself, $N \leq 10$. In our calculation, $N=200)$ 
To implement this model, we need to determine the values of the futures prices (out to $16 \mathrm{yrs}$.) and the corresponding volatility for these maturities.

\subsection{Electricity Production Value $P_{0}$}

To begin, we need to come up with the electricity production value $P_{0}$, which is the risk-neutral expected present value of 25 years' production, ${ }^{1}$ considering $2 \%$ drift rate in electricity price. Unlike in the Monte Carlo method, in the binomial model method, we use the summation of value instead of cash flow to calculate the present value of electricity. Since the future price is the risk-neutral forecast of the spot price, which indicates $F=$ $E^{*}\left(S_{t}\right)$. Let $S$ be the spot price of electricity at time $t: S_{0}=0.43 \mathrm{RMB} / \mathrm{kWh}$. With drift rate $\mu_{S}=2 \%$, we have $E^{*}\left(S_{t}\right)=S_{0} \exp \{.02 t\}$.

First, we calculate the value of electricity production every year from year 1 to year 25, which is installed capacity multiplid by unit generating capacity multiplied by the difference between spot price of electricity at time $t$ and unit operation and maintenance cost, and then discount them back to today and sum up all the present values. The value of the production is taxed for income tax, but the operating and maintenance cost is exempted from income tax and only taxed for the value-add tax, which splits the equation into two parts. When calculating value for every year, we considered the annual decline of unit generating capacity, and it turns out the annual expected rate of increase in power prices (2\%) exactly offsets the magnitude annual decreased production (also $2 \%$ ) of value-added

\footnotetext{
${ }^{1}$ We assume all expectations in our analysis are risk-neutral. It is only with respect to the risk-neutral distribution that prices today are the discounted present values using the risk free rate. Zhang et al. (2017) are silent on the distinction between risk-neutral and physical expectations. Because their analysis would otherwise be incorrect, we are assuming they refer to risk-neutral expectations.
} 
tax part. Then the value of expected electricity production $P_{0}$ is given by ${ }^{2}$

$$
\begin{aligned}
& P_{0}=E^{*}\left[(1-\tau) \sum_{t=1}^{25} \frac{\operatorname{IC~ugc~}\left(S_{t}-\text { uomc }\right) \exp \{-.02 t\}}{(1+r)^{t}}\right. \\
& \left.-\pi \sum_{t=1}^{25} \frac{\mathrm{IC} \mathrm{ugc} S_{t} \exp \{-.02 t\}}{(1+r)^{t}}\right] \\
& =(1-\tau) \operatorname{IC~ugc} \sum_{t=1}^{25} \frac{S_{0} \exp \{.02 t\} \exp \{-.02 t\}-\text { uomc exp }\{-.02 t\}}{(1+r)^{t}} \\
& -\pi \mathrm{IC} \mathrm{ugc} \sum_{t=1}^{25} \frac{S_{0} \exp \{.02 t\} \exp \{-.02 t\}}{(1+r)^{t}} \\
& =(1-\tau) \operatorname{IC~ugc}\left[\sum_{t=1}^{25} \frac{S_{0}}{(1+r)^{t}}-\text { uomc } \sum_{t=1}^{25} \frac{\exp \{-.02 t\}}{(1+r)^{t}}\right] \\
& -\pi \mathrm{IC} \mathrm{ugc} \sum_{t=1}^{25} \frac{S_{0}}{(1+r)^{t}} \\
& =(1-\tau) \operatorname{IC~ugc}\left(S_{0} \frac{1}{r}\left[1-\frac{1}{(1+r)^{25}}\right]-\text { uomc } \sum_{t=1}^{25} \frac{1}{(1+r+0.02)^{t}}\right) \\
& -\pi \mathrm{IC} \operatorname{ugc} S_{0} \frac{1}{r}\left[1-\frac{1}{(1+r)^{25}}\right] \\
& =\operatorname{IC~ugc~} S_{0} \frac{1}{r}\left[1-\frac{1}{(1+r)^{25}}\right](1-\tau-\pi) \\
& -\operatorname{IC} \text { ugc }(1-\tau) \text { uomc } \frac{1}{r+0.02}\left[1-\frac{1}{(1.02+r)^{25}}\right]
\end{aligned}
$$

Similarly, the price of $\mathrm{CO}_{2}$ is $p_{0}=0.12 \mathrm{RMB} / \mathrm{kW}$, multiplied by installed capacity and unit generating capacity, we can get value of carbon credit for year $t$ without considering any drift rates. The annual expected rate of increase in carbon prices (2\%) also offsets

\footnotetext{
${ }^{2}$ There are two proximations in the calculation: $\exp \{.02 t\} \cong(1+0.02)^{t}$ and $(1+t)^{t}(1+0.02)^{t} \cong$ $(1+r+0.02)^{t}$.
} 
the magnitude annual decreased production (2\%). Then we discount all 25 years' values to today. Let $V_{0}$ (Credit) represent the present value of $\mathrm{CO}_{2}$ credits at time 0 , calculating as an annuity,

$$
V_{0}(\text { Credit })=\operatorname{IC~ugc~} p_{0} \frac{1}{r}\left[1-\frac{1}{(1+r)^{25}}\right] .
$$

The exercise price today if there is no option to wait is $k_{0}=12000 \mathrm{RMB} / \mathrm{kW}$, considering $\mathrm{T}$ years to maturity and annual decreased investment cost (-6\%), exercise price today is $K_{T}$

$$
K_{T}=k_{0} \exp \{-.06 T\}
$$

\subsection{Project Value $V$ and Volatility $\sigma$}

In this section, we derive $V$ and the magnitude of $\sigma . V$ is the total value of the project today when the embedded option is $T$ years to maturity, which contains subsidy, electricity production value and carbon credits.

To begin, if $D$ is the required subsidy,

$$
V=D+P_{0}+V_{0}(\text { Credit })
$$

Note that $V$ only captures the value of every component as of today, and joint volatility for $V$ reflects every volatility component, and $V$ will evolve from the given value today. ${ }^{3}$ Now, we need to figure out $\sigma$ which captures the joint effect of different factors, taking differences yields

$$
d V=d D+d P_{0}+d V_{0}(\text { Credit })
$$

\footnotetext{
${ }^{3}$ Under Black-Scholes, the risk-neutral process is $\frac{d S}{S}=r d t+\sigma d z$.
} 
and since $D$ is a const. (i.e., $d D \equiv 0$ ),

$$
\frac{d V}{V}=\frac{P_{0}}{V} \frac{d P_{0}}{P_{0}}+\frac{V_{0}(\text { Credit })}{V} \frac{d V_{0}(\text { Credit })}{V_{0}(\text { Credit })} .
$$

The second aspect we need to derive is the $\sigma$ to apply in the call-option formula (4.1). We obtain that by recognizing (4.7) and (4.4). Assuming zero correlations throughout, ${ }^{4}$ in the equation below, and because there are linear relationships between $P_{0}$ and $S_{0}, V_{0}$ (Credit) and $p_{0}, K$ and $k_{t}$, we recognize $\sigma\left(\frac{d P_{0}}{P_{0}}\right)=\sigma\left(\frac{d S_{0}}{S_{0}}\right)=2 \%, \sigma\left[\frac{d V_{0}(\text { Credit })}{V_{0}(\text { Credit })}\right]=\sigma\left(\frac{d p_{0}}{p_{0}}\right)=$ $3 \%$, and $\sigma\left(\frac{d K}{K}\right)=\sigma\left(\frac{d k}{k}\right)=4 \%$ :

$$
\begin{aligned}
\sigma^{2}\left(\frac{d V}{V}-\frac{d K}{K}\right) & =\sigma^{2}\left(\frac{d V}{V}\right)+\sigma^{2}\left(\frac{d K}{K}\right) \\
& =\left(\frac{P_{0}}{V}\right)^{2} \sigma^{2}\left(\frac{d P_{0}}{P_{0}}\right)+\left[\frac{V_{0}(\text { Credit })}{V}\right]^{2} \sigma^{2}\left[\frac{d V_{0}(\text { Credit })}{V_{0}(\text { Credit })}\right]+\sigma^{2}\left(\frac{d K}{K}\right)
\end{aligned}
$$

That means in the application of the American call-option formula $C(\cdot)$ :

1. $V$ changes according to (4.5), which is driven by changing value of $D ; K_{T}$ changes according to (4.4)

2. The volatility is given by the square-root of (4.8)

3. In our case, the early exercise of an American-style option under risk-neutral expectations is not determined by stock's expected return; instead, all we need to know for optimal early exercise is the volatility of the asset and how much in-the-money we are.

\footnotetext{
${ }^{4}$ This zero-correlation assumption repeats what the authors did in their article, but we suspect it is empirically counterfactual.
} 
4. Recalling that $D$ is part of $V$ in (4.5), apply the American option-formula for $T=1$ through $T=16$ and find $D_{T}$ for each date that satisfies the two equivalent conditions for early-exercise. The first one is :

$$
V-K_{T}=C\left(V, K_{T}, r, \sigma, T, N\right)
$$

which indicates early exercise occurs when the difference between project value and exercise value is equal to option's intrinsic value, which also means that the option' s time value has vanished. An equivalent condition is: $\Delta=1.0$. The $\Delta$ is a ratio comparing the change in the price of an asset, to the corresponding change in the price of its derivative, which in our case, is the price of its option. For an Americanstyle option, the $\Delta$ increases and reaches 1.0 at the early-exercise threshold value. When the option is sufficiently deep in-the-money, the $\Delta$ stays at 1.0 . This means that if the project increases in price by $\$ 1$, the price of the option embedded in it will rise by $\$ 1$, all else being equal. Only when the difference between the $V_{T}$ and $K_{T}$ is equal to call option value and at the same time $\Delta$ reaches 1.0 , the investor would exercise today, otherwise they are better to wait. $\Delta$ value can be found in the DerivaGem software (Figure 4.1).

That will provide us $D_{1}$ through $D_{16}$. The subsidy that incentivizes investors to optimal immediate exercise of the option is the maximum value of all subsidies. It is also the minimum subsidy the government should pay, in order to cover the largest subsidy the investors need and encourage them to do a project today. Then the final equation is

$$
D=\max _{T}\left\{D_{1}, \ldots, D_{16}\right\}
$$




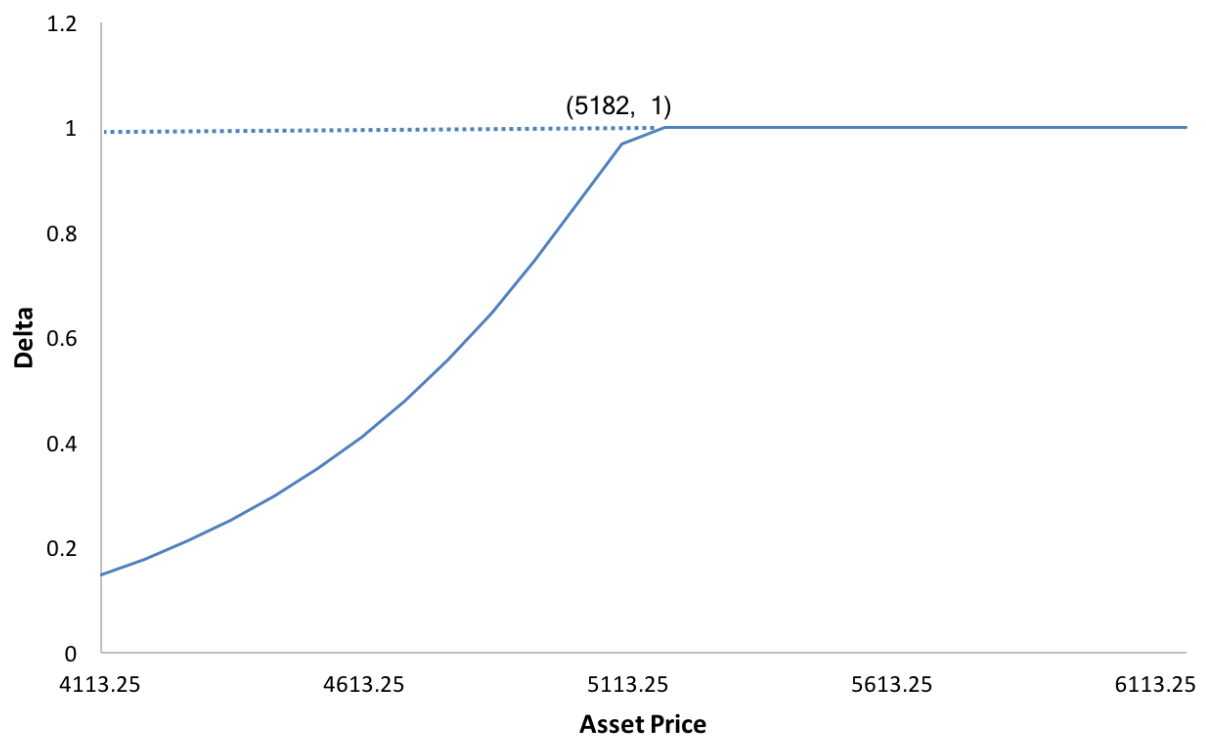

Figure 4.1: Early Exercise Condition 


\section{Chapter 5}

\section{Result Analysis}

To begin, calculate $P_{0}$ from (4.2), and $V_{0}$ (Credit) from (4.3)

$$
\begin{aligned}
P_{0}= & \operatorname{IC~ugc~} S_{0} \frac{1}{r}\left[1-\frac{1}{(1+r)^{25}}\right](1-\tau-\pi) \\
& -\operatorname{IC~ugc}(1-\tau) \text { uomc } \frac{1}{r+0.02}\left[1-\frac{1}{(1.02+r)^{25}}\right] \\
= & 2554
\end{aligned}
$$

For $V_{0}$ (Credit),

$$
\begin{aligned}
V_{0}(\text { Credit }) & =\operatorname{IC~ugc~} p_{0} \frac{1}{r}\left[1-\frac{1}{(1+r)^{25}}\right] \\
& =1 \times 1500 \times 0.12 \times \frac{1}{.08}\left[1-\frac{1}{(1+.08)^{25}}\right] \\
& =1921
\end{aligned}
$$

For option valuation, we need inputs of future price, strike price, volatility, risk-free rate and time to expiration. The subsidy is determined iteratively, by solving (4.9) and let $\Delta=1.0$ which is the conditions for early exercise. The risk-free rate and time to expiration are known from Table 3.2, the strike price is equal to $K$, and the option's future price is equal to $V_{T}$, the volatility is the joint volatility for subsidy, market price of electricity and carbon credit as shown in (4.8), number of steps $N$ is 200. First, as the subsidy value is 
included in the $V_{T}$, we fix the subsidy at some value, compute $V_{T}$ and the volatility, and then iterate to compute the subsidy at which the early-exercise occurs. Then feed that back into the volatility calculation and see if the process converges.

Taking $T=1$ as an example,

$$
\begin{gathered}
K_{1}=12000 \times \exp (-0.06 \times 1)=11301 \\
V_{1}=D+P_{0}+V_{0}(\text { Credit })=D+2554+1921=D+4475
\end{gathered}
$$

In order to let $V_{1}$ at least as large as $K_{1}, D$ should at least be 6826 . Assume $D=6830$, then $V_{1}=11305$, and put $V_{1}=11305$ into the equation (4.8),

$$
\begin{aligned}
\sigma_{1} & =\sqrt{\left(\frac{P_{0}}{V_{1}}\right)^{2} \sigma^{2}\left(\frac{d P_{0}}{P_{0}}\right)+\left[\frac{V_{0}(\text { Credit })}{V_{1}}\right]^{2} \sigma^{2}\left[\frac{d V_{0}(\text { Credit })}{V_{0}(\text { Credit })}\right]+\sigma^{2}\left(\frac{d K}{K}\right)} \\
& =4.06 \%
\end{aligned}
$$

Through the iteration process, $\operatorname{try} \operatorname{larger} D$ until $V_{1}-K_{1}=$ option value and $\Delta=1$, producing the threshold value and that is when the investor would exercise today. Besides, whenever $V_{1}$ changes, $\sigma$ will be automatically changed. When the early exercise condition is met, $V_{1}=12061$, and thus $D_{1}=7586$.

Another example of $T=16$,

$$
\begin{gathered}
K_{16}=12000 \times \exp (-0.06 \times 16)=4595 \\
V_{16}=D+P_{0}+V_{0}(\text { Credit })=D+4475
\end{gathered}
$$

In order to let $V_{16}$ at least as large as $K_{16}, D$ should at least be 120 . Assume $D=120$, then 
$V_{16}=4595$, and put $V_{16}=4595$ into the equation,

$$
\begin{aligned}
\sigma_{16} & =\sqrt{\left(\frac{P_{0}}{V_{16}}\right)^{2} \sigma^{2}\left(\frac{d P_{0}}{P_{0}}\right)+\left[\frac{V_{0}(\text { Credit })}{V_{16}}\right]^{2} \sigma^{2}\left[\frac{d V_{0}(\text { Credit })}{V_{0}(\text { Credit })}\right]+\sigma^{2}\left(\frac{d K}{K}\right)} \\
& =4.34 \%
\end{aligned}
$$

Repeat the iteration process, try larger $D$ until $V_{16}-K_{16}=$ option value and $\Delta=1$, and that will be the threshold value. When the early exercise condition is met, $V_{16}=5134$, and thus $D_{16}=659$. Using the same approach, we can get all subsidy from $T=1$ to $T=16$, and the optimal subsidy level is found through equation (4.10).

For the purpose of comparing results, just as original authors do, we also have two scenarios, one with carbon credit existing and one without. For the one without carbon credits, we just need to put $V_{0}$ (Credit) $=0$ in the model, and the $V_{T}$ and $\sigma$ will be automatically changed. Everything else remains constant in the model. The results for those two scenarios are shown in Table 5.1.

We can see a volatility $(\sigma)$ versus strike price $(K)$ trade off between $T=1$ and $T=16:$ As the total volatility embedded in the option is $\sqrt{\sigma^{2} T}$, with $T=1, K$ equals 11301 which is high but total volatility is only $\sqrt{\sigma^{2} T}=\sqrt{\sigma^{2} 1}=\sigma$; with $T=16, K$ equals 4595 which is low but total volatility is $\sqrt{\sigma^{2} T}=\sqrt{\sigma^{2} 16}=4 \sigma$. With the current numerical values, the strike price $K$ has greater impact. Which means that the lower strike price reduces the European-option value more than high volatility increases it, so the subsidy to induce immediate exercise can be lower.

There has been a purported proof that if the maturity of the option is longer, the option is more valuable, thus the subsidy needed for early exercise is larger. If that is the case, we only need to calculate the subsidy for the option that has the longest maturity if we 
Table 5.1: DerivaGem Results of Subsidy

\begin{tabular}{cccc}
$\mathrm{T}$ & Strike Price (K) & With Carbon Credit & Without Carbon Credit \\
\hline 16 & 4595 & 659 & 2560 \\
15 & 4879 & 969 & 2872 \\
14 & 5181 & 1299 & 3202 \\
13 & 5501 & 1648 & 3553 \\
12 & 5841 & 2019 & 3924 \\
11 & 6202 & 2411 & 4318 \\
10 & 6586 & 2827 & 4735 \\
9 & 6993 & 3267 & 5175 \\
8 & 7425 & 3732 & 5641 \\
7 & 7885 & 4223 & 6133 \\
6 & 8372 & 4740 & 6651 \\
5 & 8890 & 5282 & 7194 \\
4 & 9440 & 5849 & 7761 \\
3 & 10023 & 6434 & 8348 \\
2 & 10643 & 7026 & 8941 \\
1 & 11301 & 7586 & 9502
\end{tabular}

want to find the maximum subsidy. However, that proof does not always hold. We know from European options on futures that the partial derivative of the call option value with respect to $T$ is ambiguous. It can be positive or negative depending on whether the option is in- or out-of-the-money. Since we can represent the American-style option as European option plus the early exercise premium, the American option is likely to inherit many of properties of the European option. Thus, we need to calculate all $D$ from $T=1$ to $T=16$ in order to find the optimal subsidy.

Given the cost input assumptions on technology costs and commodity prices, Table 5.2 shows the amount of money that an investor would need to make an investment today. With carbon trading, the investors need $7586 \mathrm{RMB} / \mathrm{kW}$ and without carbon trading, they need $9502 \mathrm{RMB} / \mathrm{kW}$. Taking the number of steps up to a maximum of 500 will increase 
accuracy, but only decrease the subsidy from $7586 \mathrm{RMB} / \mathrm{kW}$ to $7579 \mathrm{RMB} / \mathrm{kW}$.

Table 5.2: Results Comparison

\begin{tabular}{ccc} 
Cases & Monte Carlo -Zhang et al & Binomial Model -Our article \\
\hline Without Carbon Trading & 8073.3 & 9502 \\
With Carbon Trading & 7072.3 & 7586
\end{tabular}

Regarding the higher value of the difference that occurs between the with carbon trading case and without carbon trading case, here are our analysis and some implications: There is consistency of our two estimates, taking $T=1$ as an example,

Starting from $D_{\text {with }}=7586$, and with $V_{0}($ Credit $)=1921$, we have

$$
V-K_{1}=C\left(V=D+4475, T=1, \sigma_{w i t h}=0.0405\right)
$$

which is satisfied by $D_{\text {with }}=7586$. Now, for the same $T=1$,

$$
V-K_{1}=C\left(V=D+2554, T=1, \sigma_{\text {without }}=0.0403<\sigma_{\text {with }}\right)
$$

If we kept $\sigma$ at $\sigma_{\text {with }}$, then we have the result

$$
V-K_{1}=C\left(V=D+2554, T=1, \sigma_{\text {with }}=0.0405\right)
$$

which implies that

$$
D=7586+1921=9507
$$

However, since $\sigma_{\text {without }}<\sigma_{\text {with }}, D_{\text {without }}$ should be somewhat less than 9507 , which it is, 9502.

The possible two implications of the analysis are: a) If our $V_{0}$ (Credit) value 1921 is correct, then the value difference in their analysis, which is 1001 , cannot be correct. b) If $V_{0}($ Credit $)=1001$, then our computation of $V_{0}$ (Credit) might be wrong. 


\section{Chapter 6}

\section{Conclusion}

In this paper, we take the advantages of the binomial model to implement subsidy valuation in Chinese renewable energy investment. This paper provides Chinese government with references of subsidy setting and provides Chinese energy investors with references to choose the timing of operating a project. In the energy investment area, the real options method has been proved to be an effective way to reflect the true value of energy projects. Due to the unforeseeable price fluctuations for oil, natural gas, and electricity, energy investors can take advantages of the flexibility on the timing of operating a project, which is also recognized as an option embedded in a project, thus bringing extra value to a project. In other words, the traditional NPV method is not proper anymore because it fails to account for future uncertainties. For renewable energy development, setting a subsidy level is a hard and important. By using the real option method, the true value of the project can be known and the subsidy will be more accurate. For option pricing, the binomial model is more efficient and simple than Monte Carlo method. For the American style option, the Monte Carlo simulation requires laborious Longstaff-Schwartz model. In contrast, the binomial model merely calls for implementation of a binomial lattice, and some of this software is freely accessible in models such as DerivaGem. This paper can also be extended to other countries for future analysis by adjusting tax rate and the data for three main parameters. 
Appendix 


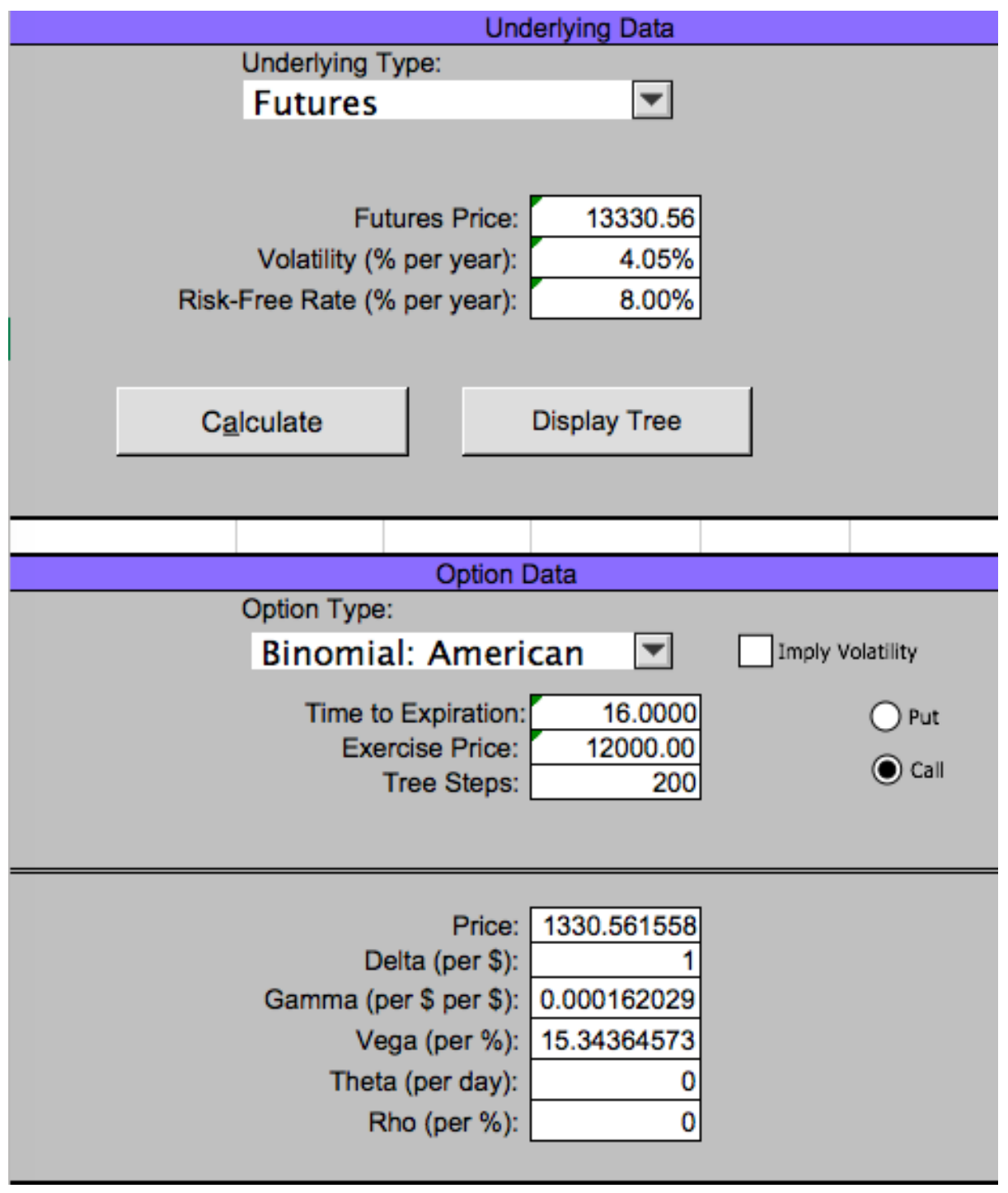

Figure A.1: DerivaGem Display 


\section{References}

1. Bloomberg New Energy Finance (BNEF) .2018. http: / / healthcaremenu . net / 2018 / 01/18/bnef-hedging-bets-on-chinas-solar-installations-in-2018/

2. Chinese photovoltaic Industry Alliance (CPIA). China Resources and Energy Association (CREIA). China photovoltaic development report. Beijing: Chinese photovoltaic Industry Alliance and China Resources and Energy Association [in Chinese]; 2013.

3. Fernandes, Bartolomeu, Jorge Cunha, Paula Ferreira, The use of real options approach in energy sector investments, Renewable and Sustainable Energy Reviews, Volume 15, Issue 9, 2011, Pages 4491-4497, ISSN 1364-0321,

4. Jia Qiuyi. Pricing American Options using Monte Carlo Methods. Department of Mathematics, Uppsala University. 2009. http: / /www. diva-portal.org/smash/get/ diva2:301061/FULLTEXT01.pdf

5. Hon, Robert. Monte Carlo and Binomial Simulations for European Option Pricing. Leeds University. 2013. https://minerva.leeds.ac.uk/bbcswebdav/orgs/SCH_ Computing/FYProj/reports/1213/Hon.pdf

6. Insley M. A real options approach to the valuation of a forest investment. J Environ Econ Manag 2002;44:471?92.

7. Litzenberger, Robert H. and Nir Rabinowitz, Backwardation in Oil Futures Markets: Theory and Empirical Evidence, Journal of Finance, Vol. L, No. 5, December 1995, pp. 1517 - 1545.

8. McDonald, Robert L. and Daniel R. Siegel, The Value of Waiting to Invest, Quarterly Journal of Economics, Vol. 101, No. 4, Nov. 1986, pp. 707 - 728.

9. Ministry of Finance and State Administration of Taxation. Notice on the tax of PV power generation project. Beijing: Ministry of Finance and State Administration of Taxation [in Chinese]; 2013.

10. Nadine Gatzert, Thomas Kosub, Risks and risk management of renewable energy projects: The case of onshore and offshore wind parks, Renewable and Sustainable Energy Reviews, Volume 60, 2016, Pages 982-998, ISSN 1364-0321

11. National Development and Reform Commission (NDRC). Notice of NDRC on Reducing the Price of Coal-fired Electricity and Electricity Prices for Industrial and Commercial Use in 2015. Beijing: National Development and Reform Commission [in Chinese]; 2015. 
12. Natural Resources Defense Council (NRDC). The Road From Paris: China's Progress Towards Its Climate Pledge. 2017. https: / / www. nrdc.org/sites/default/files/ paris-climate-conference-China-IB.pdf

13. Pringles, Rolando, Fernando Olsina, Francisco Garcs. Real option valuation of power transmission investments by stochastic simulation, Energy Economics, Volume 47, 2015, Pages 215-226, ISSN 0140-9883

14. Ronn, Ehud. Valuation of Oil Fields as Optimal Exercise of the Extraction Option, Managing Energy Price Risk (3rd. Edition), Risk Books, Vincent J. Kaminski(ed.), London, 2004.

15. Schwartz Eduardo S. and James E. Smith, Short-term Variations and Long-term Dynamics in Commodity Prices, Management Science, 46 (7), pp. 893 - 911, July 2000.

16. State Administration of Taxation. Corporate Income Tax Law of the People' s Republic of China. Beijing: State Administration of Taxation [in Chinese]; 2007.

17. Tompaidis, Stathis and Yang, Chunyu, Pricing American-Style Options by Monte Carlo Simulation: Alternatives to Ordinary Least Squares (September 30, 2014). Journal of Computational Finance, Vol. 18, No. 1, 2014. Available at SSRN: https://ssrn.com/ abstract $=2789401$

18. X. Jin Yang, Hanjun Hu, Tianwei Tan, Jinying Li, China's renewable energy goals by 2050, Environmental Development, Volume 20, 2016, Pages 83-90, ISSN 2211-4645

19. Zhang MM, Zhou P, Zhou DQ. A real option model for renewable energy investment with application to solar photovoltaic power generation in China. Energy Econ 2016;59:213-26.

20. Zhang MM, Zhou DQ, Zhou P. Optimal feed-in tariff for solar photovoltaic power generation in China: a real options analysis. Energy Policy 2016;97:181-92.

21. Zhang MM, Zhou DQ, Zhou P, Chen HT. Optimal design of subsidy to stimulate renewable energy investments: The case of China. Renewable and Sustainable Reviews 2017; 873-88371

22. Zhang MM, Zhou DQ, Zhou P. A real option model for renewable energy policy evaluation with application to solar PV power generation in China. Renew Sustain Energy Rev 2014;40:944-55.

23. Zhou WJ, Zhu B, Chen DJ, Zhao FX, Fei WY. How policy choice affects investment in lowcarbon technology: the case of $\mathrm{CO} 2$ capture in indirect coal liquefaction in China. Energy 2014;73:670?9.

24. Zhu L, Fan Y. A real options-based CCS investment evaluation model: case study of China's power generation sector. Appl Energy 2011;88:4320?33. 